\title{
FOUR CASES OF
}

\section{BILHARZIASIS UNDER THYMO-BENZOL 'IREATMENT.}

BY

C. M. EKINS, M.R.C.S., L.R.C.P.

(Director, Alexandria Hospital, Eigypt).

Case I.-Mohamed Ahmed Aly, an Egyptian : male, of about 23, a policeman, admitted to hospital on 22nd November, 1914, with symptoms of bilharziasis of the bladder; painful and frequent micturition and hæmaturia. The urine was examined immediately after admission, and living miracidia found.

$\mathrm{He}$ was first put on buchu and hyoscyamus, and light diet; subsequently irrigation of the bladder with pot. permang. 1 : 4,000 was started, the bowels being kept all the time freely open.

On 20th December, he was given the thymo-benzol preparation, $0 \cdot 20$ and 15 grams respectively, t.d.s., and this he took for a couple of days, during which period he was more or less intoxicated.

The dose was reduced for this reason from 15 grams to 4 grams, and the patient continued to take' 4-gram doses t.d.s. for six days, and three more searches in the urine on different days proved the persistence of active miracidia. Bowels regular, no alteration of pulse.

Patient discharged on 31st December, unimproved.

Case II.-Ahmed Mansoor Admed, an Egytian male of about 35, labourer, was admitted on 16th December, 1914, with straining at stool with blood and mucus. Stools examined and bilharzia ova found, urine searched and living miracidia also found.

The patient's bowels were first opened by a dose of sod. sulph.; felix mas was then administered internally, and tannin enemata for two days.

On 19th December, he was given the thymo-benzol treatment, 020 of the former and 15.00 of the latter, four times daily, but symptoms of intoxication supervened. (T'he patient kept laughing and was full of hallucinations). 'This big dose had to be reduced next day to 4 grams only t.d.s.

Meantime, repeated examinations of the stools and urine proved positive, active miracidia present. The treatment was continued until 26th December, and, one more examination of the fæeces and urine proving positive, this case was sent out on 3rd January, 1915, no better. 
Case III.-Mohamed Aly, a boy of 12, Egyptian, admitted on 19th December, 1914, with symptoms of dysentery, the nature of which was revealed by a microscopical examination of the stools which proved the presence of ova and miracidia.

On the 21st and 2:2nd, patient was given small doses of calomel, which acted well, producing four or five lax motions in the 24 hours.

On the $23 \mathrm{rd}$, he was given the thymo-benzol, 0.20 of the former and 300 of the latter, t.d.s., which treatment he kept taking for six days, the bowels open all the time. Except that the boy was slightly drowsy, there has been no change worth mentioning.

Result.-Miracidia which were alive on the first examination, were not found on a second examination made on the 24th, and another on the $26 \mathrm{th}$, but in repeating the search on the $28 \mathrm{th}$, a few living miracidia were found. The boy was discharged on the 31st, unimproved as far as the bilharzia is concerned.

Case IV.-Aly Soliman, a policenuan of about 22, admitted on the 18th December, with a complaint of passing blood and mucus in his stools. For two days his bowels were opened by 10-yram doses of sod. sulph. in the morning at the time that his stools were sent to the bacteriologist, who reported absence of bilharzia and presence of ankylostoma ova. The patient was put on the thymol treatment for ankylostomiasis, while tannin enemata were also administered. Bilharzia ova were looked for again next day, but neither they nos amobæ were found.

Three days later, a further search in the stools still proved absence of bilharzia ova and amobæ, but revealed existence of trichomonas. Next morning, i.e., on the 24th, bilharzia ova were found, though not one miracidium out of the shell. On the 26th, another examination prover negative to both bilharzia and trichomonas.

Before starting any thymo-benzol treatment the stools were examined once more, on the 28th, this time living miracidia being found the patient was given six doses of the preparation in two days, 0.30 of the thymol and 3.00 of the benzol. The amount of blood passed per rectum next day was even worse than before, and on further examination living miracidia were again found.

The patient, a policeman, was eventually discharged from the service. 
Dr. F. M. SAndwith : As this paper was sent to me I would like to tell you its previous history. About a year ago Dr. William Robertson, of Natal, whom I have not the pleasure of knowing, wrote to me and told me he had discovered a cure for bilharziasis. As you know, there is no known cure for that disease, and I was very pleased to hear of a cure for it. Shortly afterwards he sent an extract from a lay paper, published in Natal, to one of the Secretaries of this Society, and it was published in our Transactions in Nov., 1914. It was stated that it invariably cured the patient, anc, curiously enough, he said in the paper that the patients never suffered from intoxication. I am always pleased to hear of any cure, but I like to have it confirmed, and therefore I wrote to Egypt and asked whether they would mind trying this treatment and letting me know the result. Then the war came and I did not hear anything; so I wrote again, and had a reply that they had not tried it in Cairo, but that Dr. Ekins had tried it in Alexandria and found it of no use. They said they would send me his paper, and they sent this paper you have just heard, which is now open for discussion. Dr. Ekins found these four cases were not benefited by the drug, and he wrote to say that the intoxicating effect was a great nuisance, because you always had to be holding the patients down in their beds. Now it rests for you to decide between the two experiences of Dr. RoBERTson and of Dr. Ekins who found no advantage in using the drug.

Fleet-Surgeon P. W. BASSETt-SMITH: There was a paper by Dr. RoBertson; a short time ago, in the British Medical Journal, which no doubt a good many read, and it is an extreme disappointment to find that what appeared to be very important statements are of doubtful value. It sertainly seems that not only is the drug unlikely to do good but it may possibly be harmful, and anyone reading the article in the British Medical Journal would be led into error.

Dr. Feuix Paez: Thymo-benzol has been used in Caracas with very good results by Dr. Gonzalez Rincones in the treatment of bilharziasis, according to the formula of Dr. RoBertson, from Natal. This consists in a mixture of one gram and eight centigrams $(1.80)$ ofbenzol and of fifteen centigrams $(0.15)$ of thymol. Some cases have yielded to this treatment. 
Dr. F. M. Sandwith: I do not know whether the meeting would be interested in hearing that many years ago, when I first learnt that thymol was useful for ankylostomiasis, $I$ hoped it would be of some use for bilharziasis, and I gave it in all the doses I knew how. I often gave small doses of three grains three or four times a day. I did not give the benzol with it. Dr. RoBERTson in his original paper wrote that he first of all tried thymol and found it of value, then he added benzol with very great success.

Fleet-Surgeon P. W. BassetT-Smith: I was in hopes that this treatment might have been of use for schistomiasis in China, which is due to the $S$. japonicum parasite and which disease is still more unfavourable to health than the bilharziasis in Egypt. One hoped the drug could have been used in China for this disease, especially as there is no known cure for it at present. 